\title{
A Hammer-Impact, Aluminum, Shear-Wave Seismic Source
}

Open-File Report 2007-1406

U.S. Department of the Interior

U.S. Geological Survey 


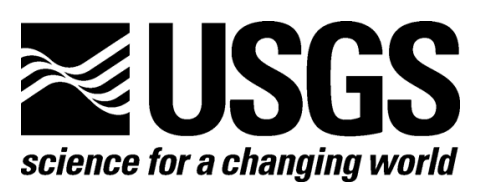

\section{A Hammer-Impact, Aluminum, Shear-Wave Seismic Source}

By Seth S. Haines

Open-File Report 2007-1406

U.S. Department of the Interior U.S. Geological Survey 


\section{U.S. Department of the Interior DIRK KEMPTHORNE, Secretary}

\section{U.S. Geological Survey \\ Mark D. Myers, Director}

U.S. Geological Survey, Reston, Virginia 2007

For product and ordering information:

World Wide Web: http://www.usgs.gov/pubprod

Telephone: 1-888-ASK-USGS

For more information on the USGS - the Federal source for science about the Earth, its natural and living resources, natural hazards, and the environment:

World Wide Web: http://www.usgs.gov

Telephone: 1-888-ASK-USGS

Suggested citation:

Haines, S. S., 2007, A Hammer-impact, aluminum, shear-wave seismic source, U.S. Geological Survey Open-File Report 2007-1406, 5 p., available only online at http://pubs.usgs.gov/of/2007/1406/.

Any use of trade, product, or firm names is for descriptive purposes only and does not imply endorsement by the U.S. Government.

Although this report is in the public domain, permission must be secured from the individual copyright owners to reproduce any copyrighted material contained within this report. 


\section{Contents}

Abstract

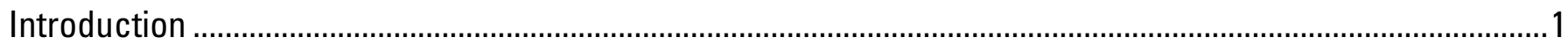

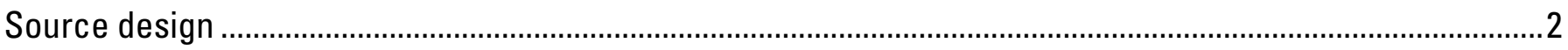

Discussion and Conclusions.....................................................................................................................

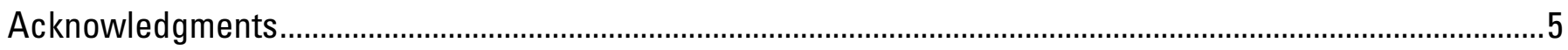

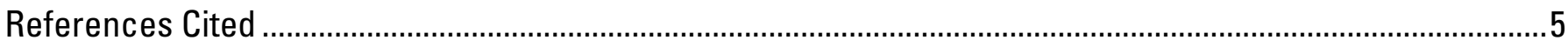




\title{
A Hammer-Impact, Aluminum, Shear-Wave Seismic Source
}

\author{
By Seth S. Haines
}

\section{Abstract}

Near-surface seismic surveys often employ hammer impacts to create seismic energy. Shearwave surveys using horizontally polarized waves require horizontal hammer impacts against a rigid object (the source) that is coupled to the ground surface. I have designed, built, and tested a source made out of aluminum and equipped with spikes to improve coupling. The source is effective in a variety of settings, and it is relatively simple and inexpensive to build.

\section{Introduction}

Near-surface shear-wave seismic surveys typically employ horizontally polarized ( $\mathrm{SH}$ ) waves because they are more easily distinguished from compressional $(\mathrm{P})$ waves, and they generally do not convert to $\mathrm{P}$ waves as readily as vertically polarized shear (SV) waves. We can create SH waves in many different ways, but the most common involve inputting horizontal ground motion at the earth's surface. We record the resulting energy with horizontal geophones. Both the source and the geophones are oriented perpendicular to the SH-wave survey transect.

An optimal SH-wave source allows for the creation of two opposite polarities of seismic energy for better identification of true $\mathrm{SH}$-wave energy. It should give repeatable results, providing virtually identical energy with each usage. The source must employ an efficient coupling mechanism so that maximum energy, with broadband frequencies, enters the ground. This is generally accomplished with some combination of mass holding it down and spikes holding it laterally stable. Finally, the source must be convenient and simple to use, readily transportable, and able to provide a brief cycle time so that surveys can be conducted quickly.

Various workers have used a number of different horizontal sources over the years. Hasbrouck (1983) describes what is often referred to as the "golf shoe" source (fig. 1); it is made of heavy steel, has a spiked base, and offers good repeatability with proper use. The golf shoe weighs approximately 40 $\mathrm{kg}$, and thus can lead to difficult logistics for an extended field campaign. In addition, the vertical impact face results in a swing geometry that some people find awkward; this awkwardness can result in diminished strike-to-strike repeatability and reduced data quality. The wooden source shown in figure 1 provides a lightweight alternative $(14 \mathrm{~kg}$ ) that has proven quite effective in some circumstances (for example, the studies described by Ellefsen and others, 2007). We find that this wooden source is most effective on pavement or hard ground, but that coupling is not optimal on rough ground, which is likely caused by the absence of spikes. In addition, the wooden source is not sufficiently durable to withstand years of use, and the location of the impact face almost directly between the legs of the hammer swinger is awkward for many people. Pugin and others (2006) present SH high-frequency data that were collected using hammer impacts on a roller that is coupled to the ground with the weight of a vehicle. 
Liu and others (1996) describe an air-powered impulsive SH source that is also weighted with a vehicle. Ghose (2002) describes SH data acquisition using a horizontal vibrator source. Each of these sources has its advantages, but none is clearly superior under all circumstances. In order to provide a repeatable, convenient, hammer-impact, SH source for use in our near-surface surveys, I created a new source.

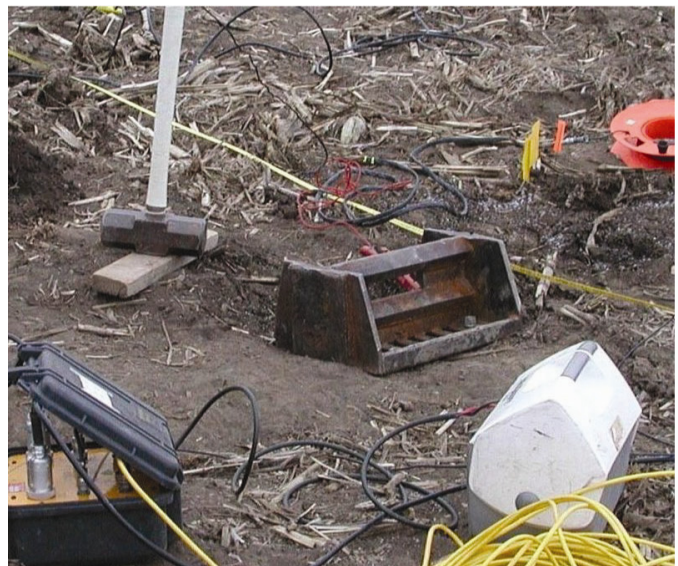

(a)

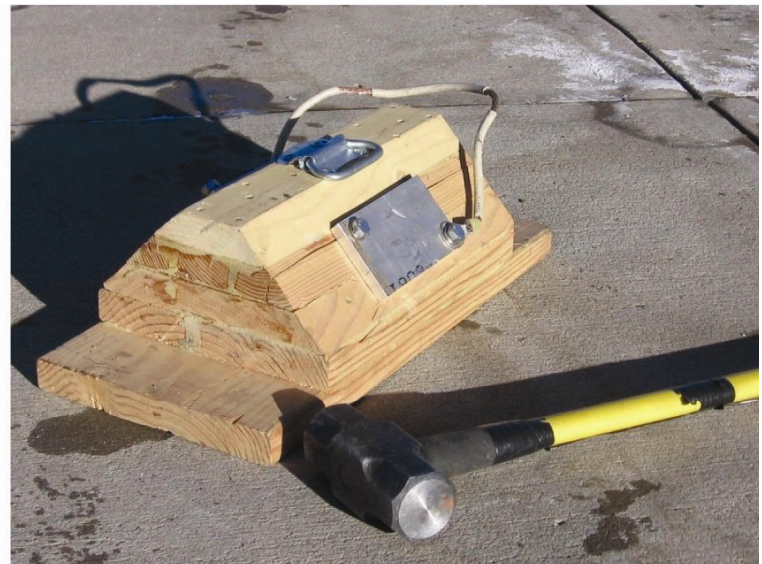

(b)

Figure 1. The steel golf shoe source (a) and the wooden source with metal strike plates (b).

The aluminum source described here was designed to provide a comfortable strike stance for the hammer swinger, which leads to improved repeatability and overall data quality. The source is inexpensive to construct and simple to use. Weight is kept to a minimum $(25 \mathrm{~kg})$ while retaining the strength necessary for extended use and repeated hammer impacts. This report describes the design and construction of this source, and concludes with some suggestions for improvements on the current design.

\section{Source design}

The source is built primarily from 2-cm thick 6061-T6 alloy aluminum plate. The original version was constructed entirely from this material, but the use of thicker aluminum block for the impact plates is a substantial improvement in the current version that is described here. One piece of plate (Figures 2a and 3) makes up the base, with holes for the ground-coupling spikes. The holes are counter-sunk on the bottom to provide space for the nuts that attach the spikes. Two longitudinal rails are welded to the base plate and provide rigid support for the impact plates. The rails are made out of aluminum plate, and their design is shown in Figure 2b. The impact plates (Figure 2c) must be made of thicker material in order to withstand a long period of use and abuse; aluminum deforms considerably when subject to thousands of hammer impacts. A $15 \times 24 \times 10 \mathrm{~cm}$ aluminum block, machined to shape, has proven effective and long-lasting. These blocks are bolted to the longitudinal rails using $17-\mathrm{cm}$ long, 1.5 -cm diameter ( $5 / 8$ inch) grade- 5 bolts, in order to facilitate replacement of the impact plates. Finally, a rope may be tied through the holes in the rails to provide a carrying handle. 


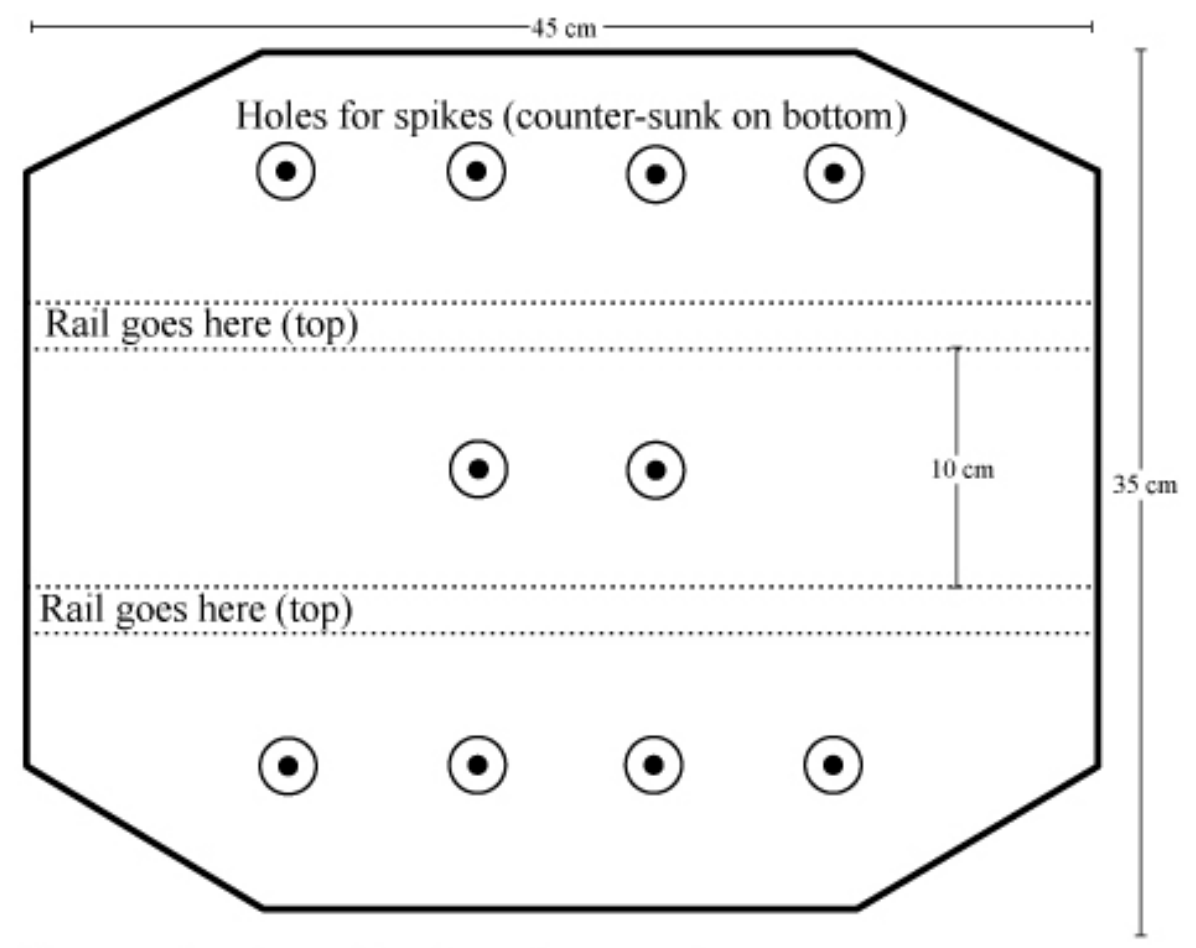

(a) Base plate, 2-cm aluminum plate. Need one.

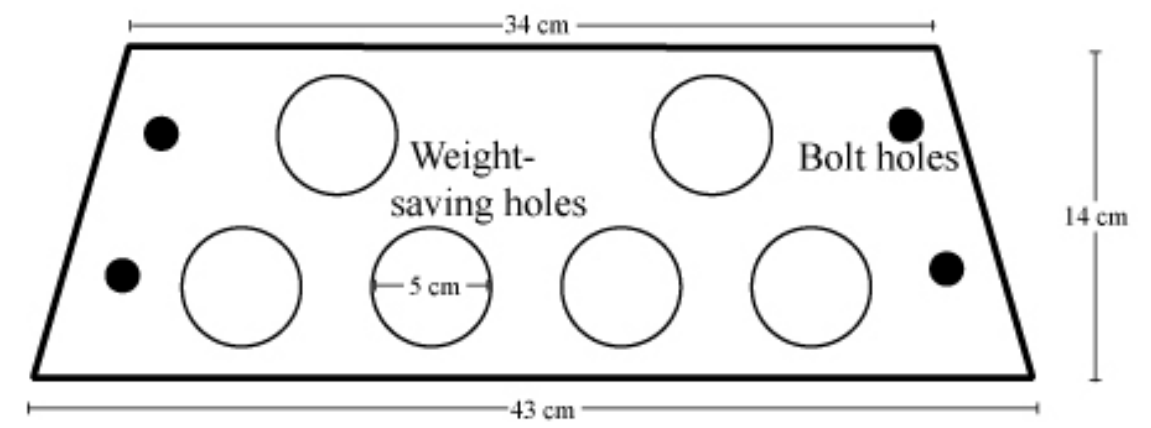

(b) Rails, 2-cm aluminum plate. Need two.

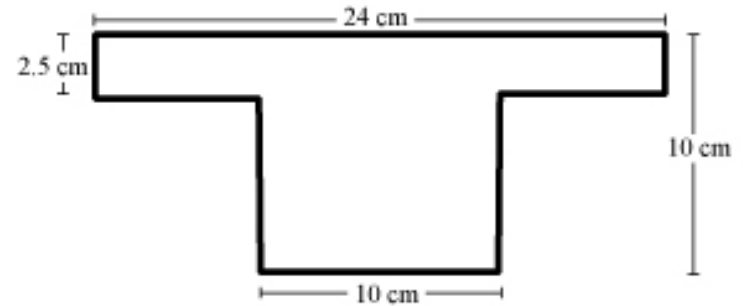

(c) Impact plates, 15-cm thick. Need two.

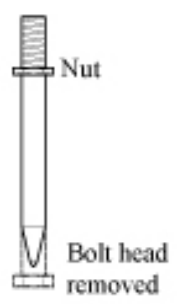

(d) Spikes, need 10+.

Figure 2. Sketches of the components of the source. Base plate (a) and rails (b) are made of 2-cm thick aluminum plate. Impact plates (c) are made of aluminum blocks. Spikes (d) are made of steel bolts with the heads cut off. Note that I now recommend eliminating or reducing the size of the holes in the rails. The hole configuration leads to weakness that results in deformation. 


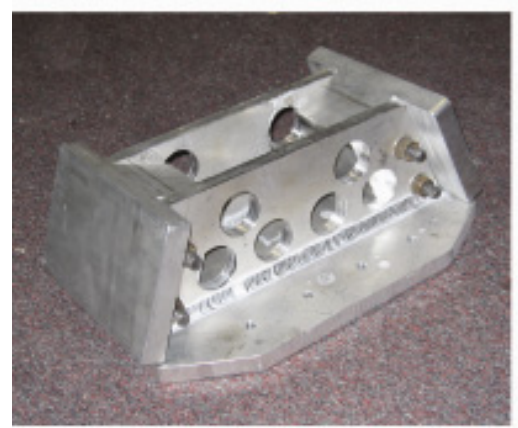

(a)

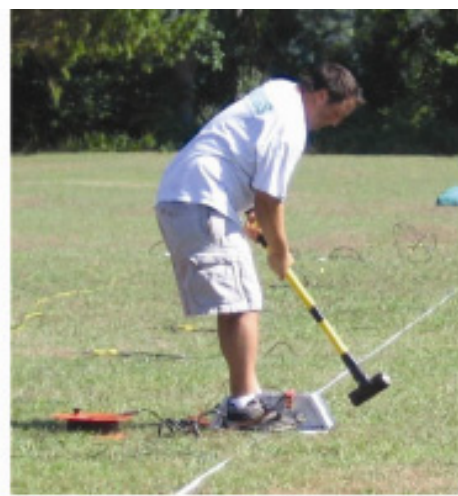

(b)

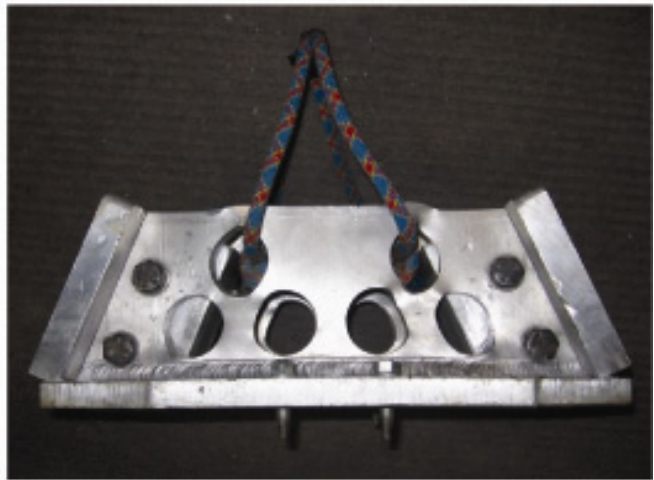

(c)

Figure 3. Photos of the source (a) with spikes removed, and the source in use for field data collection (b). After several thousand impacts, the rails show considerable deformation (c), indicating that the holes weaken the source. The holes were previously circular, but now all are deformed. The rope handle and some spikes are also visible.

The ground-coupling spikes are made of $1-\mathrm{cm}$ diameter ( $3 / 8 \mathrm{inch}$ ) bolts, with the head cut off and the remaining smooth section machined to a moderate point (Figure 2d). A half-thickness nut on the threaded part of the spike rests against the underside of the source base plate, and a lock washer and nut on the top side of the base plate hold the spike in place. I use two different spike lengths depending on conditions. For hard ground, gravel and cobbles, etc., I find $5.5-\mathrm{cm}$ long spikes to be effective. For softer soils, grassy areas, etc., I find the longer 10.5- $\mathrm{cm}$ spikes to be preferable. The spikes are easily changed, or removed for use on pavement or other such surfaces.

\section{Discussion and Conclusions}

The source is effective and has proven reliable through two years of usage. The basic design is very functional, but the durability has room for improvement even in this second version. It has withstood approximately 10,000 impacts and remains functional, but it does show signs of failure (figure 3c). The primary change that I would make for future versions is to redesign the hole pattern in the rails. Removing material saves weight and also allows for a rope handle to be threaded through. But the current configuration of holes weakens the rails so that they deform laterally after extended use. Smaller holes, with larger amounts of aluminum between them, would create a more durable source. Perhaps it would be best to drill only small holes for the rope handle, and otherwise leave the rails intact.

The current impact plate design is very strong and has deformed very little after extended use. However, I suspect that the same would be true for a somewhat modified design. I would try making the plate thinner (perhaps $8 \mathrm{~cm}$ total thickness instead of $10 \mathrm{~cm}$ ) in order to save weight.

Clearly, the impact plates would not need to be nearly as thick if they were made of a different material. Because the impact plates are bolted, rather than welded, to the aluminum framework, the use of other materials is feasible. I don't necessarily advocate a different design, but it is something to consider. Steel is one option, although it rings very loudly when struck with a hammer - an inconvenience that can become more of a major issue over the course of an extended survey. Also, steel is considerably more dense than aluminum, so it would be difficult to avoid a weight increase. 
The source described here provides one option for near-surface SH surveys. I find it to be wellsuited to a variety of applications, and consider it my standard choice for most surveys. It is light enough that it can be readily moved between locations, it is inexpensive to build, and it provides consistent data with a high degree of strike-to-strike repeatability.

\section{Acknowledgments}

I am very grateful to Paul Wigton, as well as to Carl Stoddard and Roy Kipfinger for help with the construction and improvement of this seismic source.

\section{References Cited}

Ellefsen, K., Burton, B., Lucius, J., Haines. S., Fitterman, D., Witty, J., Carlson, D., Milburn, B., and Langer, W., 2007, Field demonstrations of five geophysical methods that could be used to characterize deposits of alluvial aggregate: U.S. Geological Survey Scientific Investigations Report 2007-5226.

Ghose, R., 2002, High-frequency shear wave reflections from shallow subsoil layers using a vibrator source: sweep cross-correlation versus deconvolution with groundforce derivative: Society of Exploration Geophysicists $72^{\text {nd }}$ Annual International Meeting, Expanded Abstracts.

Hasbrouck, W. P., 1983, Sketches of a hammer-impact, spiked-base, shear-wave source: U.S. Geological Survey Open-File Report 83-917, 7 p.

Liu, H., Maier, R., and Warrick, R., 1996, An improved air-powered impulsive shear-wave source: Bulletin of the Seismological Society of America, v. 86, p. 530-537.

Pugin, A., Sargent, S., and Hunt, L., 2006, SH- and P-wave seismic reflection using landstreamers to map shallow features and porosity characteristics in Illinois: Symposium on the Application of Geophysics to Environmental and Engineering Problems, Proceedings, p. 1094-1109. 